\title{
Epistemic Injustice: Towards Uncovering Knowledge of Bisexual Realities in Social Work Research
}

\section{Gio Iacono}

\begin{abstract}
Lesbian, gay, bisexual, transgender and queer (LGBTQ) individuals experience health risks, with bisexuals experiencing higher levels of health risk compared to heterosexuals, gays and lesbians. These disparities are often attributed to stressors related to minority status. While similarities among LGBTQ experiences exist, it is plausible that bisexuals experience unique forms of marginalization, which may help explain the documented health disparities. Bostwick and Hequembourg highlight unique forms of marginalization that bisexuals experience vis-a`-vis microagressions, falling within the realm of the epistemic. Fricker's work on epistemic injustice emphasizes marginalization particularly as it is related to knowledge and experience. Drawing on this scholarship, this paper provides a review of existing literature on the bisexual experience, and a discussion to provide a critical lens on bisexual marginalization in society and the minimal attention received in social work research. Approaches to increase bisexual visibility and attention in social work research will be discussed. Some approaches include: developing a queer theoretical perspective in practice and research to allow for greater problematization of social categories; and making a concerted effort to promote research that is inclusive of minority populations within the sexual and gender minority population group. This might include groups with intersecting points of marginalization, such as racialized and gender diverse individuals.
\end{abstract}

Keywords: Bisexuality; epistemic injustice; microaggression; research

Bisexuality was historically seen as a way to understand physical sexual characteristics (i.e., exhibiting characteristics of both male and female sexes) through the fields of anatomy and physiology, as well as individual gender expressions (i.e., a combination of masculinity and femininity) associated with biological sex (MacDowall, 2009). Eventually, the science community started using the term "bisexual" as an exclusive term to understand a specific kind of sexuality, particularly sexual attraction to both cisgender men and women (not including trans and other gender non-binary identities; Robinson, 2017). Much of the literature on bisexuals has been collapsed with that of other sexual minorities such as gays and lesbians (Fredriksen-Goldsen, 2011; Wallace, Cochran, Durazo, \& Ford, 2011), which may obscure accurate population estimates, as well as risk factors and realities of the bisexual community. While considering factors that may create variation among estimates of the bisexual population, such as limitations of survey methods, the Williams Institute reported estimates of the percentage of adults who self-identify as bisexual across nine population-based surveys, including national surveys from Canada, the United Kingdom, Australia, Norway, and the United States (Gates, 2011). They reported estimates of the bisexual population ranging from $1.2-2.1 \%$ for non-US surveys, and $0.7-3.1 \%$ for USbased surveys. Furthermore, a large-scale 2014 study by the National Health Interview Survey (NHIS) found that 0.7 percent of Americans identify as bisexual (Ward,

Gio Iacono, MSW, is a Ph.D. candidate at Factor-Inwentash Faculty of Social Work, University of Toronto. 
Dahlhamer, Galinsky, \& Joestl, 2014). Research is increasingly showing that bisexuals experience significant health and mental health disparities compared to heterosexuals, gays and lesbians (Bostwick, Hughes, \& Everett, 2015; Fredriksen-Goldsen, Kim, Barkan, Balsam, \& Mincer, 2010; Gorman, Denney, Dowdy, \& Medeiros, 2015). It has been hypothesized that these disparities are largely due to discrimination (e.g., identity dismissal, dating exclusion, blame for spreading diseases) by heterosexual and gay/lesbian communities (Robinson, 2017).

Within social work, research and discussions on sexual and gender diversity beyond gay and lesbian experience is largely absent (McPhail, 2004; Mulé, 2008). Empirical evidence points to unique forms of bisexual marginalization, vis-a `-vis microagressions, that fall within the realm of the epistemic (Bostwick \& Hequembourg, 2014; Ross, Dobinson, \& Eady, 2010; Tjepkema, 2008). As the study of knowing or knowledge, epistemology concerns itself with the nature of knowledge, how we come to knowledge, what we know, why we know, whether what we know is true, and understanding the limits of knowledge (Steup, 2014). As epistemology involves understanding human knowledge construction, it is important to approach bisexual knowledge erasure and unintelligibility within an epistemological framework (Fricker, 2007). Given the small size of the bisexual population, and minimal attention placed on bisexuality in social work research, this paper aims to provide a review of existing literature on the bisexual experience and begin a discussion to increase understanding of, and provide a critical lens on bisexual marginalization and invisibility — referring to how the legitimacy and acceptability of bisexuality is questioned or denied in society at large.

Epistemic injustice refers to when one experiences prejudice and/or discrimination based on one's construction of knowledge; one is wronged epistemically (i.e., wronged as a knowledge giver) (Fricker, 2007). Epistemic injustice includes microagressions, first introduced by Pierce (1970), which are everyday verbal, behavioral, and environmental slights and indignities that are hostile and discriminatory in nature towards racialized communities, sexual and gender minorities, and other marginalized groups (Sue, 2010).

\section{Background and Significance}

Sexual and gender identities (e.g., heterosexual, gay, lesbian, bisexual, transgender, queer) can be seen as culturally specific and socially constructed (Miller, André, Ebin, \& Bessonova, 2007). A common and historical understanding of bisexuality tells us that bisexual individuals are only attracted to males and females, with the biological deterministic assumption that sex and gender always co-occur and correspond with each other (Mikkola, 2012). Bisexuality has been traditionally regarded as a binary conception (e.g., attraction to only two genders), which has been challenged in recent years (Robinson, 2017). This paper aims to move beyond a binary conception of bisexuality and sexuality overall. For the purposes of this paper, the term "sexual and gender minority" (SGM) as a population identifier is generally considered to encompass distinct identities separate from the "sexual and gender majority" (e.g., heterosexual, cisgender), a minority that may include lesbian, gay, bisexual, transgender, and queer groups (LGBTQ), among many others. While, for the sake of convenience, these groups are all considered part of the same overarching SGM category or community (Weiss, 2003), they have been shown to 
experience varying levels of risk for different health outcomes (Bostwick \& Hequembourg, 2014; Institute of Medicine, 2011). Placing sexual/gender identity in a majority or minority category is simplistic and perpetuates a binary way of understanding phenomena.

Research is beginning to uncover health disparities among minority groups within the broader SGM population (e.g., Ross, et al., 2010). Bisexuals may be at a higher risk than heterosexual individuals and, in some cases, at a higher risk than gay and lesbians for health and mental health problems, higher rates of mental health service utilization, substance use, as well as suicidality (e.g., Bostwick \& Hequembourg, 2014; Case et al., 2004; Diamant \& Wold, 2003; Jorm, Korten, Rodgers, Jacomb, \& Christensen, 2002; Kerr, Santurri, \& Peters, 2013; Ross et al., 2010; Sarno \& Wright, 2013; Tjepkema, 2008). Meyer (1995) posits that such disparities are often attributed to stressors related to minority status, including experiences of prejudice and discrimination. The Meyer (1995) minority stress model, widely used to understand various social factors that influence health in minority populations, posits that stigma and discrimination in society influence the health and mental health of SGM. Multiple minority stressors such as homo/bi/trans-phobic prejudice and stigma, victimization, internalized homo/bi/trans-phobia, and hiding one's sexual or gender identity, have been found to have adverse effects on the health and mental health of SGM populations (Klein \& Dudley, 2014; Lehavot \& Simoni, 2011). However, Meyer (2003) acknowledges that the minority stress model fails to differentiate between differing realities that fall under the SGM banner. Bisexuals may experience different stress-related experiences compared to other sexual minorities (Bostwick \& Hequembourg, 2014).

\section{Social Work and Sexual/Gender Minority Issues}

Social work is a profession that aims to support individuals, families, groups and communities in enhancing their well-being. In addition to individual and group problems, the profession also strives to promote social justice and is concerned with larger social problems such as poverty and institutional and systemic oppression, such as homophobia and transphobia (Drover, 2013). Though social work draws from the fields of psychology, sociology, philosophy, law, medicine and political science, to name a few, the values and approaches that inform social work thought, practice, and research center on the concept of person-in-environment. This approach considers the relationships and interactions between individuals, their support resources, communities, and societal and social forces. This focus on relationships is argued to be a distinguishing feature of the social work profession (Canadian Association of Social Workers [CASW], 2000). Accordingly, discussion of SGM issues, from a social work perspective, may allow for a deeper and richer understanding of sexual/gender minority issues that could lead to potential action in the social work profession, as well as in disciplines from which social work borrows.

In social work, theory, research or practice, individuals are typically classified by group membership in order to conduct research, to plan political action and to inform practice, policy, and education. Social workers aim to advocate on behalf of oppressed groups; however, the assumptions about the groups' social categories (e.g., gay, lesbian, bisexual, woman, newcomer, black, and so on) remain largely unchallenged (McPhail, 2004). Binary notions (e.g., male/female, gay/straight) prevail in many of social work's traditional theoretical perspectives (e.g., structural social work). These notions are not 
merely in the field of social work but also found within many disciplines (e.g., psychology, sociology, law, etc.) and reflect the dominant culture (Weiss, 2003). Within social work, an appreciation of the diversity of sexual and gender identity is largely absent; it "has limited presence in policy, and lacks adequate funding, impacting on programming and services, detrimentally affecting practice” (Mulé, 2008, para.16). The field of social work, with its ethical standards, could lead the way for other disciplines with respect to challenging these binary notions of identity. McPhail (2004) argues that incorporating critiques informed by postmodern and queer theoretical perspectives is beneficial to the social work profession since these approaches align with the profession's value of selfdetermination, which allows individuals to define themselves as opposed to being defined by others. However, it has been argued that the social work profession holds a desire for certainty (Martin, 1996), thus making it challenging to incorporate these perspectives. Furthermore, LGBTQ activists in social work and other disciplines have worked hard to increase political and social power through group visibility and identification. The reluctance by the social work profession to deconstruct and strip down concepts of social group identity is maintained by a concern that these already marginalized groups may become even more invisible and powerless (McPhail, 2004). Queer theoretical perspectives in social work, while increasing, may be met with ongoing resistance.

\section{Binary "Logic"}

Since there is a strong assumption of binary categories pertaining to sexual and gender identity (e.g., gay/straight, male/female) within social work, research in this area is generally dichotomized, which can foster rigid identity assumptions, a homogeneous understanding of research participants and results, and a divide between "normal" and "deviant" behavior, as well as masking inherent variation in different groups and populations (Johnson \& Repta, 2012). Bringing greater awareness to the complexity of sexual and gender identity could have transformative effects on how research is conducted. Further, sexual and gender identity can be seen as temporally fluid, as they are not necessarily fixed points in one's life (Voss, Browne, \& Gupta, 2014). Some scholars in social work have begun to acknowledge and recognize the increasing evidence that sexual and gender identity are not binary categories, that binary categories might not even be an accurate way of understanding these phenomena (Burdge, 2007; Gringeri \& Roche, 2010). While an understanding that the binary model may be flawed has gained some traction in social work research, the majority of researchers continue to disregard this possibility, reinforcing the dichotomous paradigm (Rassi, 2011).

Critiques from postmodern, poststructural, and queer theory perspectives, as well as from individuals or groups (e.g., transgender, bisexual, intersex) who do not "fit" neatly into binary categories remain absent within social work literature and research (Gringeri \& Roche, 2010). The binary model is so deeply embedded and taken for granted within social work that it sometimes seems inescapable. The binary conceptualization, related to Western logocentric thought, can be seen as the "desire for a centre or original guarantee of all meanings" which, according to philosopher Derrida, has characterized Western philosophy since Plato (Baldick, 2015, p.191). From a Western perspective, binary terms are perceived as hierarchical, with one term valued (or "privileged") and the other devalued 
(or "marginalized”), as well as mutually exclusive and oppositional (Sands, 1996). Social work theory, research, and practice largely follow this model (e.g., power/oppression, privilege/marginalization), remaining an essentialist enterprise (McPhail, 2004). For instance, at the risk of simplifying the rise of the gay/lesbian movement, gays and lesbians defined themselves as members of a sexual minority rather than challenging the construction of sexual identity in general (Rust, 2000). However, it could be that the magnitude of stigma and oppression experienced by gays and lesbians at that time would have made challenging constructions of sexual identity unfeasible and too radical during that period.

Societal power structures and relations rely on an essentialist binary model; non-binary realities such as bisexuality upset these power structures and relations. It should not be surprising then that it is these "misfits" that are the most stigmatized, marginalized, and discriminated against in our society. Power structures and relations also exist within the SGM population, commonly known as the LGBT community. According to Weiss (2003), as the "LGBT community" was forming (for various sociopolitical reasons), power relations arose that led to four distinct groups (i.e., L/G/B/T), each with different social and power positions, with the binary identities garnering more power (p.53). Discrimination and prejudice by gays and lesbians against non-binary identities such as bisexuals and transgender people can be seen as a reaction to political and social pressures that exist within the greater society at large. These reactions by gays and lesbians can be seen as coming from societal pressure to maintain certain binary power structures, in what has been

argued to be an "accommodationist" attempt to fit into society, providing the message, for the sake of political progress, that gays and lesbians are the same as heterosexuals ("we are just like you;” Weiss, 2003, p.30). Thus, attempting to ameliorate these conditions (e.g., discrimination, microagressions, and erasure) that exist within the greater society at large for bisexuals and other non-binary identities will require challenging the rigid notions of essentialist dualities and their underlying structural power dynamics.

\section{Challenges in Research and Scholarly Inquiry}

Research on sexual minorities, in social work and other disciplines, generally likens bisexuals' experiences of marginalization to that of the experiences of gays and lesbians (Mays \& Cochran, 2001), a comparison which reinforces a homogenous and narrow analysis of factors that negatively affect the health and well-being of bisexuals. This narrow analysis further contributes to the misunderstanding of, and invisibility, of bisexual realities and their unique experiences of marginalization. The Institute of Medicine (2011) acknowledged the problematic treatment of minority identities and realities (e.g., transgender, bisexual) within the SGM population (i.e., LGBTQ community), asserting that there are distinct population groups that fall under the SGM banner, with their own specific health needs. This statement reveals some recognition that various SGM groups are often combined as a single entity for research (and for advocacy purposes). For research purposes, it is important to consider the complexity and intersectionality of the experiences of SGM individuals, as they are diverse and shaped by factors such as race, ethnicity, socioeconomic status, age, geographical location, and many more. Intersectionality 
considerations in SGM research are critical as these intersectional factors can further exacerbate existing health-related issues (Thoma, Huebner, \& Rullo, 2013).

Even more puzzling, it has been argued that even queer theory, an epistemological position that appears to be significantly aligned with and supportive of bisexual realities, has also abandoned bisexuality as a topic of inquiry (Bostwick \& Hequembourg, 2014; Erickson-Schroth \& Mitchell, 2009). The influential works behind queer theory, such as those by Foucault (1978) and Butler (1991), despite being in opposition to biological binary models of gender and sexuality, have all overlooked bisexuality as a topic to be taken seriously (Gurevich, Bailey, \& Bower, 2009). For instance, Callis (2009) writes, in making reference to Foucault's (1978) analysis of the homosexual identity, that:

...with no medical discourse, no scientifically granted truth and no reverse discourse, it is little wonder that bisexual identity has formed more slowly than others; the fact that Foucault's work can be used to explain this difference between homosexual and bisexual identities confirms that bisexuality would have been a fruitful topic for Foucault to explore...the usefulness of bisexual identity to buttress Foucault's work also points to the utility of the subject for modern queer theorists drawing on Foucault. (p. 226)

While Foucault's theory of discourse can explain the Western construction of gays and lesbians (Foucault, 1978), it could also be used to provide an explanation of the lack of salience around bisexual identity. Ultimately, greater diversity in SGM research is needed, a point of view that places a stronger focus on diverse bisexual populations, especially in the areas of mental health and health. Further, while similarities among SGM groups' experiences of marginalization do exist, it is plausible that bisexuals experience unique forms of marginalization due to their bisexual identity, which may help explain the documented health disparities among bisexuals (Dobinson, MacDonnell, Hampson, Clipsham, \& Chow, 2005; Rainbow Health Ontario, 2015). Some of these documented disparities among bisexuals include: higher reports (Canadian and US) of anxiety, depression, suicidality, and self-harm, relative to gay and lesbian identified individuals (Kerr, et al., 2013; King et al., 2008; Steele, Ross, Dobinson, Veldhuizen, \& Tinmouth, 2009; Tjepkema, 2008).

Research has not been conducted evenly across SGM populations, with more research focusing on gays and lesbians than on bisexual and transgender people (Rainbow Health Ontario, 2015). Without "epistemological data to legitimize" bisexual issues, it will be challenging to develop and implement interventions and services for bisexuals, and to convince funders that bisexual health and mental health research and services are important (Miller et al., 2007, p.4).

\section{Epistemic Injustice vis-a`-vis Microagressions}

Drawing on the theoretical work of Fricker (2007), Bostwick and Hequembourg (2014) present a framework for understanding the lived experience of bisexual individuals and the marginalization they experience. Within this framework, they “...posit that differences in prejudicial experiences do exist for bisexual groups, and that such differences reside in the realms of the epistemic, yet have very real implications...” (p. 488). 


\section{Epistemic Injustice}

The philosophical work by Fricker (2007) provides an explanation of how injustices relating to categories of knowledge and experience adversely affect bisexuals. Fricker (2007) argues that individuals and groups can be wronged, silenced, and made unintelligible in their capacity as knowers. Furthermore, epistemic relations occur within an environment of justice and fairness that is influenced by structural power dynamics and mutual understandings of what social identities should look like (Bostwick \& Hequembourg, 2014). Fricker (2007) suggests that there are two types of epistemic injustices. The first, called testimonial injustice, involves being wronged or not taken seriously in one's capacity as a giver of knowledge. As an example of testimonial injustice, Fricker (2008) states: “a speaker receives a prejudicially deflated degree of credibility from a hearer... an example might be that a jury does not believe someone simply because of the colour of his skin" (p.69).

The second type of epistemic injustice, called hermeneutic injustice, occurs when an individual's social experience is obscured or made unintelligible due to a structural prejudice and prevention through collective understanding (Hawley, 2011). In hermeneutic injustice, society lacks a conceptual framework for understanding or taking seriously the claims of someone's reality or experience. As an example of hermeneutical injustice, Fricker (2008) notes:

the difficulty of making sense of homosexual desire as a legitimate sexual orientation in a cultural-historical context where homosexuality is interpreted as perverse or shameful. In such a context, the gay subject cannot make proper sense of his sexuality, owing to the fact that gay people as such were prevented from making a full contribution to collective resources for social meaning, with the result that the forms of understanding available for making sense of homosexuality were crucially uninformed and distorted. (p. 70)

Similarly, bisexuals can experience testimonial and hermeneutical injustice in society (e.g., Bostwick \& Hequembourg, 2014; Ross et al., 2010; 2016; Sarno \& Wright, 2013, which may be addressed through various methods in social work research and practice).

\section{Microagressions}

Microagressions, regarded as common slights and insults, drive and maintain oppressive discourses (Smith, Shin, \& Officer, 2012) and have been shown to have very significant consequences for sexual minorities. Sue (2010) posits that microaggressions are "the brief and commonplace daily verbal, behavioral, and environmental indignities that communicate hostile, derogatory, or negative racial, gender, sexual orientation, and religious slights and insults” (p. 5). The literature suggests that the psychological impact of microagressions for SGM groups includes chronic stress, anxiety, depression, and lowered self-esteem, to name a few (Nadal, Rivera \& Corpus, 2010). In evaluating differences in the experiences of microaggressions among bisexuals and homosexuals, Sarno and Wright (2013) found significant differences between homosexuals and bisexuals for different types of microaggressions (e.g., assumed to be straight). Bisexuals had more difficulty than their homosexual counterparts with internalized homophobia, biphobia, and 
identity confusion. A review of the literature confirms these findings (e.g., Cox, Berghe, Dewaele, \& Vincke, 2010; Kuyper \& Fokkema, 2011) and shows that a difference exists in how bisexuals experience and are affected by various forms of microagressions. Some of these differences include: higher risk for health issues, greater hostility and discrimination, and higher levels of minority stress compared to gays and lesbians (e.g., Herek, Gillis, \& Cogan, 1999; Hershberger, Pilkington, \& D’Augelli, 1997; Jorm et al., 2002).

\section{Linking Epistemic Injustice to Microagressions}

Drawing on Bostwick and Hequembourg's (2014) framework, it can be argued that testimonial and hermeneutic injustices, vis-a `-vis microagressions, are experienced by bisexuals recursively in a mutually reinforcing manner that seeks to erase bisexual individuals and communities. Various forms of microagressions that drive the invisibility, erasure, and silencing of bisexual reality in research and other domains of social life place bisexuality, as a way of knowing and being, outside of the realm of intelligibility (Bradford, 2004). Epistemic erasure can be seen as a form of injustice that creates real consequences for bisexuals and other marginalized identities. Epistemic injustice, both testimonial and hermeneutic, can translate to deeply painful experiences of exclusion and marginalization in various parts of bisexuals' lives. The dismissal (i.e., testimonial) and lack of intelligibility (i.e., hermeneutic) experienced by bisexuals through the enactment of microaggressions can have deleterious effects. Microagressions can contribute to experiences of epistemic injustice by invalidating, negating, or undermining bisexuals' lived experiences. For instance, a microaggressive statement such as "bisexuals are confused and cannot be trusted" or "bisexuals are really gay/straight" can undermine their embodied experiences and reality (Sue, Bucceri, Lin, Nadal, \& Torino, 2007). An example of epistemic injustice through microagressions in social work may be the experience of having one's sexual and/or gender identity invalidated by the practitioner's negative assumptions or indifference.

Social workers may inadvertently commit microaggressions that lead to epistemic injustice by assuming that bisexuals are either homosexual or heterosexual (Sarno \& Wright, 2013). They may do so because of dominant cultural notions of bisexuality as mentioned earlier, including the erroneous idea that bisexuality is a mere stopping place or phase of exploration until a true homosexual identity is accepted (Bostwick \& Hequembourg, 2014). Consequently, this attitude renders an enduring bisexual identity as invisible or unintelligible (Sarno \& Wright, 2013). These epistemic injustices vis-a '-vis microagressions may help explain why bisexuals have the highest rates of mental health issues among sexual minorities (King \& McKeown, 2003; Jorm et al., 2002) and why they have uniquely negative experiences within the healthcare system (Dobinson et al., 2005). For instance, because of bisexual invisibility, many healthcare providers, including LGBTQ-friendly providers, are not always competent regarding bisexuality and are perceived by bisexuals as not inclusive of their identity and reality (Dobinson et al., 2005; Ross et al., 2010; 2016). Bisexuals can also experience judgment or dismissiveness about their sexual identity from health care providers and social workers, as well as inappropriate questions about their sexual practices (Eady, Dobinson, \& Ross, 2011). Moreover, helping 
professionals may assume the sexual identity of a client who is bisexual based on the client's current sexual partner (s), thus rendering their identity and reality invisible (Eady et al., 2011; Page, 2004).

Bostwick and Hequembourg (2014) have explored the ways in which microagressions drive epistemic injustices in bisexual women. They found seven "'bisexual-specific' microaggressions routinely experienced by participants and illustrative of epistemic injustice in action: hostility, denial/dismissal, unintelligibility, pressure to change, lesbian, gay, bisexual and transgender legitimacy, dating exclusion, and hypersexuality” (p. 492). These microaggressions reinforce cultural understandings of bisexual incomprehensibility as well as illustrate how bisexuals are regarded as untrustworthy. The authors argue that "the chronic subversion of bisexual...credibility through bisexual- specific microaggressions may be key to understanding the extraordinarily high rates of depression" (Bostwick \& Hequembourg, 2014, p. 499).

Microaggressions also come from within the "community" (i.e., LGBTQ communities) that could potentially be a site of support for bisexuals. This double exclusion, from both hetero and SGM populations, can exacerbate the negative effects of microagressions and epistemic injustice (Hequembourg \& Brallier, 2009). An example that illustrates Fricker's work is the experience of bisexuals within healthcare, which either places them in a "straight" or "gay" box. The concept of bisexuality is largely disregarded or overlooked, except for in some clinics that may routinely work with SGM groups (e.g., LGBTQ sexual health clinics; Eady et al., 2011). This type of microaggression is problematic as bisexuals have unique health concerns and issues that are usually disregarded (Miller et al., 2007). Many issues, such as sexual health concerns, can be overlooked, resulting in potential harm (Eady et al., 2011). The experiences of bisexuals highlight how the prevailing monosexual paradigm and rigid binary thinking in our society leads to microagressions contributing to epistemic injustice and oppressive outcomes.

\section{Future Directions}

There is no one solid, prescriptive, answer to the multifaceted issues raised in this paper. Epistemic injustice, which translates into felt physical and psychological consequences for bisexuals, is cleverly invisible and insidious. We are in the infancy of social change with regards to sexual/gender liberation. In keeping with Bostwick and Hequembourg's (2014) analysis, the following recommendations and suggestions are offered.

\section{Queer Possibilities}

Despite queer theory's relatively minimal focus on bisexual realities, this perspective still holds great potential to address epistemic injustices experienced by bisexual individuals. Working within a queer theory epistemology, in any potential context (e.g., academia, policy, practice), can build understanding and greater awareness of the bisexual experience. In queer theory, attention is given to not only what is said, but also to what is not being said (Horn, 2012). Giffney (2009) states "there is an unremitting emphasis in queer theoretical work on fluidity, uber-inclusivity, indeterminacy, indefinability... and 
that which is unrepresentable...” (p. 8). The point of queer theory, then, with its focus on raising more questions and problematizing binary notions of sexuality/gender, is not to arrive at an answer about these issues; rather, its contribution to remedying bisexual epistemic injustices would be to bring to light issues to help improve the lives of not just bisexual-identified individuals, but also the lives of all people who are invariably impacted by the dichotomizing, binary understanding of gender, sex, sexuality, and all facets of life. The very essence of a contemporary understanding of bisexuality (i.e., understood as being attracted to multiple genders) unsettles and destabilizes categories of sexuality/gender (Robinson, 2017). Greater inclusion of bisexuality into works of queer theory would allow for a richer understanding of sexuality, as well as contribute to the undertaking of deconstructing the homo/hetero binary logic. Da umer (1999) argues that bisexuality can be conceptualized as "an epistemological and ethical vantage point" that can be used to destabilize binary categories of sexuality and gender (p.159). This viewpoint illuminates the potential for bisexuality to expose inevitable contradictions and ambiguities of all adopted identities (Gurevich et al., 2009).

More recently, sexuality researchers have described bisexuality as an umbrella term (including behavior, as a non-binary identity), that includes other non-monosexual identities (i.e., being sexually attracted to multiple genders) such as a pansexual, omnisexual, and fluid identities. This evolution refers to a shifting of perspective that emphasizes bisexuality as a non-monosexual reality that may include attraction to more than one gender (compared to more traditional views of bisexuality as being attracted to only men and women; Flanders, Lebreton, Robinson, Bian, \& Caravaca-Morera, 2017; Robinson, 2017). In recent research, pansexual individuals are generally grouped under the bisexual umbrella (Mitchell, Davis, \& Galupo, 2014), with bisexuals and pansexuals identifying in similar ways (i.e., romantic and/or sexual attractions to multiple and diverse genders, including non-binary genders; Flanders et al., 2017). Therefore, it is important to consider other non-binary forms of sexuality (e.g., pansexual, etc.) that bisexuality represents in our discussions of queering social work research and practice. Terms like pansexuality, omnisexuality, and bisexuality (as being attracted to multiple genders) can help our profession generate more complex discussions of sexuality and gender identity and further the queering of social work (Gringeri \& Roche, 2010; Robinson, 2017).

The marrying of bisexuality knowledge and queer theory allows for a stronger queer theory deconstruction enterprise, while also helping bring intelligibility to the bisexual experience, in its various forms. However, it is also important that we use identity locations, such as "bisexual," as a strategic political tool without assigning ontological integrity to this identity (Butler, 1991). From a social work perspective, it is critical that social identity groups, such as bisexuals, are intelligible in relation to LGBTQ and human rights activisms. Yet, it is also critical that we are not too rigid and limiting about social identification. This is the ongoing tension that the field of social work must grapple with: acknowledging that these social identities indeed are very much a reality for people while at the same time being careful not to simplify or dismiss the complexity that exists within a particular social category or identity. Maintaining this tension in social work — affirming a bisexual identity that is used for political strategizing without assigning ontological integrity to it - may allow for greater visibility, empowerment, and acknowledgment of 
the diverse bisexual experience while simultaneously allow for social activism that addresses bisexual marginalization which creates deeply felt social and material exclusions (Voss et al., 2014). Bringing in a queer perspective to social work allows for a problematization of social categories and offers a broader approach for understanding sexuality. This reconsideration is in line with social work's values of self-definition and social justice; queer theory allows us to acknowledge that many paths can take us there (McPhail, 2004).

\section{Transformative Research}

Research has the potential to bring about social change. The enterprise of research has the potential to hold much influence in the public arena, despite the various power relations and power differentials that limit certain types of research. Challenging sexuality and gender binaries within social work research and practice will likely come with resistance and difficulty. Queering dominant perspectives through critical analysis within social work research is particularly challenging as everything could be questioned, reinterpreted, and rendered uncertain; surely this could bring some discomfort to researchers (McPhail, 2004). Further, attaining funding for research that does not align with funders' worldviews or political agendas could be a significant barrier. Notwithstanding, upsetting normalized perspectives is necessary if we are to bring about liberatory social transformation for sexual and gender minorities. The failure to problematize these hegemonic definitions of sexual and gender identity can result in the continued marginalization for many groups, such as bisexuals.

Reflexivity can encourage researchers to examine power relations and dismantle hegemonic assumptions related to sexual and gender identity (Brookfield, 1995), and help them become more aware of what knowledge and understandings they are creating and the ways they create this knowledge (Steup, 2014). This reflexive process may be helpful for the task of problematizing binary thinking (McPhail, 2004). Working reflexively also allows for the potential to make adjustments to research questions and methods in order to be more inclusive and reflect the realities and knowledge of research participants (Ristock, 2001). There are no guarantees that reflexivity will bring about the hoped-for change in social work research practices, but it can certainly be helpful if done with integrity and authenticity.

Some other important ways, highlighted by McPhail (2004), of queering social work research include: avoiding discrete categories of gender and sexual identity in theoretical models and in explaining findings; speaking more tentatively and conditionally when attempting to make generalizations based on identity categories; and offering "disclaimers" as we attempt to wear identities lightly (Laumann, Gagnon, Michael, \& Michaels, 1994). Further, demographic questionnaires that have open-ended questions, instead of multiplechoice responses, could help with creating more freedom and fluidity with regards to participants' expressions of multiple and intersecting identities. This strategy can also have implications for dissemination of research findings, as well as help regulate the inherent power of the researcher (Fantus, 2013). Broadly, I would strongly urge social work researchers working with gender and sexual diversity to make a concerted effort to promote research that is inclusive of minority groups within the SGM population, especially 
focusing on groups with even greater intersecting points of marginalization (e.g., racial and gender diversity). Ultimately, these suggestions for social work research could create greater complexity and completeness of scientific understanding in sexual/gender diversity research and contribute to validating bisexuals' and other SGM groups' experiential knowledge, consequently reducing epistemic injustice (Bell, 2014).

\section{Embodied Knowledge and Multiple Ways of Knowing}

Queer theorist Sedgwick (2007), in confronting limitations of critical theory, argues for a "reparative reading" (p. 638) approach—alongside a critical theory approach—that takes into account the power of knowing through affect. Sedgwick appears to be calling for multiplicity in knowing, which includes both critical approaches such as queer theory and poststructuralist readings of discourse, as well as felt, embodied knowledge as an important way of knowing. Sedgwick also calls attention not only to material conditions but also to the body, with its intensities and knowledge, acknowledging emotions, tacit knowledge, and visceral lived experience (i.e., embodied knowledge). This emphasis is of critical importance, especially considering that embodied knowledge can be seen as a way of disrupting dominant forms of knowledge, and uncovering marginalized ways of knowing (Wong, 2004). Some critical social work scholars have pointed out the importance of embodied knowledge in order to engage in critical social work practice and research with social justice aims (Bai, 2001; Tangenberg \& Kemp, 2002). Bringing awareness to our embodied knowledge can provide a path to addressing epistemic injustice. For researchers committed to uncovering issues pertaining to SGM issues, moving into life's complexities can be unsettling and uncomfortable. Researchers must strive not simply to remain within the cognitive realm of knowing but also to be open to bodily and emotive knowing with respect to relating to one another and the world surrounding them (Wong, 2004). This critical awareness can help unsettle binaries and bring greater appreciation of and engagement with the fluidity of sexuality and gender.

\section{Resistance}

Building understanding and greater awareness of bisexuality as an intelligible identity can be seen as an act of resistance. Bisexuals might distance themselves or confront negative messages about their realities; they could also educate others about inaccurate understandings and stereotypes and organize or join bisexual groups that seek to engage in activism and social activities (McGrady, 2012). These approaches may help bisexuals increase their self-esteem and social support. However, resistance is also limiting; strategies such as distancing from others who enact stereotypes risk further segmenting subcultures and reproducing the negative meanings associated with a stigmatized status (Lapinski, Braz, \& Maloney, 2010). Foucault (1978) argues that SGM groups, in using new words, ideas, and concepts to describe and speak about their distinctive and personal experiences, can begin to exercise power through this resistant language. Bringing to light, through research and advocacy, someone's multi-layered, and oftentimes conflicting narratives can pave the way for a greater understanding of obscured realities (Fantus, 2013). SGM groups, in speaking their multiple truths, can feel empowered by challenging stigma and attributing stigmatization to other people’s prejudice (Thoits, 2011). 


\section{Bringing It All Together}

This paper has sought to develop a critical understanding of the realities of bisexual and other fluid identities in social work research. Preliminary suggestions for social work have been offered as a precursor to eventual action. As bisexuality is rarely discussed as a topic unto itself (McPhail, 2004), it is important to generate a discussion about strategies and actions that uncover bisexual realities within social work. This paper could be used as a launching point for interrogating binary assumptions in social work that lead to epistemic injustices for bisexuals and other fluid identities. In line with social work's approach of implementing collective social action, this writing stands in solidarity with other social work scholars' (e.g., Gringeri \& Roche, 2010; McPhail, 2004; Mulé, 2008) who advocate for greater visibility of sexual and gender diversity in social work. Given social work's values of advocacy and social justice, increasing understanding and action to address the issues outlined in this paper could also impact other professions that interact with social work. This vision is important to maintain if we are to effectively address bisexual marginalization and epistemic injustice in society.

\section{References}

Bai, H. (2001). Beyond the educated mind: Towards a pedagogy of mindfulness, in B. Hocking, J. Haskell, \& W. Linds (Eds.), Unfolding bodymind: Exploring possibility through education (pp. 86-99). Brandon, VT: Foundation for Educational Renewal.

Baldick, C. (2015). The Oxford dictionary of literary terms. Oxford: Oxford University Press. doi: https://doi.org/10.1093/acref/9780198715443.001.0001

Bell, K. (2014). Exploring epistemic injustice through feminist social work research. Affilia, 29(2), 165-177. doi: https://doi.org/10.1177/0886109913516457

Bostwick, W., \& Hequembourg, A. (2014). 'Just a little hint’: Bisexual-specific microaggressions and their connection to epistemic injustices. Culture, Health \& Sexuality, 16(5), 488-503. doi: https://doi.org/10.1080/13691058.2014.889754

Bostwick, W. B., Hughes, T. L., \& Everett, B. (2015). Health behavior, status, and outcomes among a community-based sample of lesbian and bisexual women. $L G B T$ Health, 2(2), 121-126. doi: https://doi.org/10.1089/lgbt.2014.0074

Bradford, M. (2004). The bisexual experience: Living in a dichotomous culture. Journal of Bisexuality, 4(1-2), 7-23. doi: https://doi.org/10.1300/J159v04n01_02

Brookfield, S. D. (1995). Becoming a critically reflective teacher. San Francisco: JosseyBass.

Burdge, B. J. (2007). Bending gender, ending gender: Theoretical foundations for social work practice with the transgender community. Social Work, 52(3), 243-250. doi: https://doi.org/10.1093/sw/52.3.243

Butler, J. (1991). Imitation and gender insubordination. In D. Fuss (Ed.), Inside/out: lesbian theories, gay theories (pp. 23-38). New York: Routledge. 
Callis, A. S. (2009). Playing with Butler and Foucault: Bisexuality and queer theory. Journal of Bisexuality, 9, 213-233. doi: https://doi.org/10.1080/15299710903316513

Canadian Association of Social Workers [CASW]. (2000). National scope of practice statement. Ottawa: Author.

Case P., Austin, S. B., Hunter, D. J., Manson, J. E., Malspeis, S., Willett, W. C., \& Spiegelman, D. (2004). Sexual orientation, health risk factors, and physical functioning in the Nurses' Health Study II. Journal of Women's Health (Larchmt), 13(9), 1033-1047. doi: https://doi.org/10.1089/jwh.2004.13.1033

Cox, N., Berghe, W. V., Dewaele, A., \& Vincke, J. (2010). Acculturation strategies and mental health in gay, lesbian, and bisexual youth. Journal of Youth and Adolescence, 39, 1199-1210. doi: https://doi.org/10.1007/s10964-009-9435-7

Da ümer, E. D. (1999). Queer ethics; Or, the challenge of bisexuality to lesbian ethics. In M. Storr (Ed.), Bisexuality: A critical reader (pp. 152-161). New York: Routledge.

Diamant, A. L., \& Wold, C. (2003). Sexual orientation and variation in physical and mental health status among women. Journal of Women's Health (Larchmt), 12(1), 41-49. doi: https://doi.org/10.1089/154099903321154130

Dobinson, C., MacDonnell, J., Hampson, E., Clipsham, J., \& Chow, K. (2005). Improving the access and quality of public health services for bisexuals. Journal of Bisexuality, 5(1), 39-77. doi: https://doi.org/10.1300/J159v05n01_05

Drover, G. (2013). Social work. Retrieved from http://www.thecanadianencyclopedia.ca/en/article/social-work/

Eady, A., Dobinson, C., \& Ross, L. E. (2011). Bisexual people’s experiences with mental health services: A qualitative investigation. Community Mental Health Journal, 47(4), 378-389. doi: https://doi.org/10.1007/s10597-010-9329-x

Erickson-Schroth, L., \& Mitchell, J. (2009). Queering queer theory, or why bisexuality matters. Journal of Bisexuality, 9(3-4), 297-315. doi: https://doi.org/10.1080/15299710903316596

Fantus, S. (2013). The dichotomy of sexuality: A narrative-epistemological framework for social work practice and research. Critical Social Work, 14(2), 99-113.

Flanders, C. E., LeBreton, M. E., Robinson, M., Bian, J., \& Caravaca-Morera, J. A. (2017). Defining bisexuality: Young bisexual and pansexual people's voices. Journal of Bisexuality, 17(1), 39-57. doi: https://doi.org/10.1080/15299716.2016.1227016

Foucault, M. (1978). The history of sexuality: Volume one. New York: Vintage Books.

Fredriksen-Goldsen, K. I. (2011). Resilience and disparities among lesbian, gay, bisexual, and transgender older adults. The Public Policy and Aging Report, 21(3), 3-7. doi: https://doi.org/10.1093/ppar/21.3.3

Fredriksen-Goldsen, K. I., Kim, H. J., Barkan, S. E., Balsam, K. F., \& Mincer, S. L. (2010). Disparities in health-related quality of life: A comparison of lesbians and 
bisexual women. American Journal of Public Health, 100(11), 2255-2261. doi: https://doi.org/10.2105/AJPH.2009.177329

Fricker, M. (2007). Epistemic injustice. Oxford: Oxford University Press. doi: https://doi.org/10.1093/acprof:oso/9780198237907.001.0001

Fricker, M. (2008). Epistemic injustice Pre' cis. Theoria, 61, 69-71.

Gates, G. J. (2011). How many people are lesbian, gay, bisexual and transgender? UCLA: The Williams Institute. Retrieved from http://escholarship.org/uc/item/09h684x2

Giffney, N. (2009). Introduction: The ‘q’ word. In N. Giffney \& M. O’Rourke (Eds.), The Ashgate research companion to queer theory (pp. 1-13). Burlington: Ashgate.

Gorman, B. K., Denney, J. T., Dowdy, H., \& Medeiros, R. A. (2015). A new piece of the puzzle: Sexual orientation, gender, and physical health status. Demography, 52(4), 1357-1382. doi: https://doi.org/10.1007/s13524-015-0406-1

Gringeri, C. E., \& Roche, S. E. (2010). Beyond the binary: Critical feminisms in social work. Affilia, 25(4), 337-340. doi: https://doi.org/10.1177/0886109910384194

Gurevich, M., Bailey, H., \& Bower, J. (2009). Querying theory and politics: The epistemic (dis)location of bisexuality within queer theory. Journal of Bisexuality, 9(3-4), 235-257. doi: https://doi.org/10.1080/15299710903316539

Hawley, K. (2011). Knowing how and epistemic injustice. In J. Bengson, \& M. Moffett (Eds.), Knowing how: Essays on knowledge, mind, and action (pp. 283-299). Oxford: Oxford University Press.

Herek, G. M., Gillis, J. R., \& Cogan, J. C. (1999). Psychological sequelae of hate-crime victimization among lesbian, gay and bisexual adults. Journal of Consulting and Clinical Psychology, 67(6), 945-951. doi: https://doi.org/10.1037/0022$\underline{006 X .67 .6 .945}$

Hershberger, S. L., Pilkington, N. W., \& D’Augelli, A. R. (1997). Predictors of suicide attempts among gay, lesbian, and bisexual youth. Journal of Adolescent Research, 12(4), 477-497. doi: https://doi.org/10.1177/0743554897124004

Hequembourg, A. L., \& Brallier, S. A. (2009). An exploration of sexual minority stress across the lines of gender and sexual identity. Journal of Homosexuality, 56(3), 273298. doi: https://doi.org/10.1080/00918360902728517

Horn, S. K. (2012). Is social work the work of love?: Love practice and queer doing in the process for full self-determination (Thesis). Retrieved from http://scholarworks.smith.edu/theses/633/

Institute of Medicine. (2011). The health of lesbian, gay, bisexual, and transgender people: Building a foundation for better understanding. Washington, DC: The National Academies Press.

Johnson, J., \& Repta, R. (2012). Sex and gender: Beyond the binaries. In J. Oliffe \& L. 
Greaves (Eds.), Designing and conducting gender, sex, and health research (pp. 1737). Thousand Oaks, CA: Sage. doi: https://doi.org/10.4135/9781452230610.n2

Jorm, A. F., Korten, A. E., Rodgers, B., Jacomb, P. A., \& Christensen, H. (2002). Sexual orientation and mental health: Results from a community survey of young and middle-aged adults. British Journal of Psychiatry, 180, 423-427. doi: https://doi.org/10.1192/bjp.180.5.423

Kerr, D. L., Santurri, L., \& Peters, P. A. (2013). A comparison of lesbian, bisexual, and heterosexual college undergraduate women on selected mental health issues. Journal of American College Health, 61(4), 185-194. doi: https://doi.org/10.1080/07448481.2013.787619

King, M., \& McKeown, E. (2003). Mental health and social well-being of gay men, lesbians and bisexuals in England and Wales: A summary of findings. London: MIND (National Association for Mental Health).

King, M., Semlyen, J., Tai, S. S., Killaspy, H., Osborn, D., Popelyuk, D., \& Nazareth, I. (2008). A systematic review of mental disorder, suicide, and deliberate self harm in lesbian, gay and bisexual people. Bio Med Central Psychiatry, 8(70), 1-17. doi: https://doi.org/10.1186/1471-244X-8-70

Klein, N. A., \& Dudley, M. G. (2014). Impediments to academic performance of bisexual college students. Journal of American College Health, 62(6), 399-406. doi: https://doi.org/10.1080/07448481.2014.917653

Kuyper, L., \& Fokkema, T. (2011). Minority stress and mental health among Dutch LGBs: Examination of differences between sex and sexual orientation. Journal of Counseling Psychology, 58(2), 222-233. doi: https://doi.org/10.1037/a0022688

Lapinski, M. K., Braz, M. E. \& Maloney, E. K. (2010). The down low, social stigma, and risky sexual behaviors: Insights from African-American men who have sex with men. Journal of Homosexuality, 57, 610-633. doi: https://doi.org/10.1080/00918361003712020

Laumann, E. O., Gagnon, J. H., Michael, R. T., \& Michaels, S. (1994). The social organization of sexuality: Sexual practices in the United States. Chicago, IL: University of Chicago Press.

Lehavot, K., \& Simoni, J. M. (2011). The impact of minority stress on mental health and substance use among sexual minority women. Journal of Consulting and Clinical Psychology, 79, 159-170. doi: https://doi.org/10.1037/a0022839

MacDowall, L. (2009). Historicising contemporary bisexuality. Journal of Bisexuality, 9(1), 3-15. doi: https://doi.org/10.1080/15299710802659989

Martin, B. (1996). Femininity played straight: The significance of being lesbian. New York: Routledge.

Mays, V. M., \& Cochran, S. D. (2001). Mental health correlates of perceived discrimination among lesbian, gay, and bisexual adults in the United States. 
American Journal of Public Health, 91(11), 1869-1876. doi: https://doi.org/10.2105/AJPH.91.11.1869

McGrady, P. B. (2012). Sexuality and larger bodies: Gay men's experience of and resistance against weight and sexual orientation stigma (Doctoral thesis). Retrieved from ProQuest Dissertations Publishing database (No. 3551162), http://diginole.lib.fsu.edu/islandora/object/fsu:183280/datastream/PDF/view

McPhail, B. A. (2004). Re-gendering the social work curriculum: New realities and complexities. Journal of Social Work Education, 44(2), 33-52. doi: https://doi.org/10.5175/JSWE.2008.200600148

Meyer, I. H. (1995). Minority stress and mental health in gay men. Journal of Health \& Social Behavior, 36, 38-56. doi: https://doi.org/10.2307/2137286

Meyer, I. H. (2003). Prejudice, social stress, and mental health in lesbian, gay, and bisexual populations: Conceptual issues and research evidence. Psychological Bulletin, 129(5), 674-697. doi: https://doi.org/10.1037/0033-2909.129.5.674

Mikkola, M. (2012). Feminist perspectives on sex and gender. In E. N. Zalta (Ed.), The Stanford encyclopedia of philosophy (Fall 2012, Online). Retrieved from http://plato.stanford.edu/archives/fall2012/entries/feminism-gender/

Miller, M., André, A., Ebin, J., \& Bessonova, L. (2007). Bisexual health: An introduction and model practices for HIV/STI prevention programing. New York: National Gay and Lesbian Task Force Policy Institute, the Fenway Institute at Fenway Community Health, and BiNet USA.

Mitchell, R. C., Davis, K. S., \& Galupo, M. P. (2014). Comparing perceived experiences of prejudice among self-identified plurisexual individuals. Psychology \& Sexuality, 6(3), 245-257. doi: https://doi.org/10.1080/19419899.2014.940372

Mulé, N. J. (2008). Demarcating gender and sexual diversity on the structural landscape of social work. Critical Social Work, 9(1). Retrieved from http://www1.uwindsor.ca/criticalsocialwork/demarcating-gender-and-sexualdiversity-on-the-structural-landscape-of-social-work

Nadal, K. L., Rivera, D. P., \& Corpus, J. H. (2010). Sexual orientation and transgender microaggressions. In D. W. Sue (Ed.), Microaggressions and marginality: Manifestation, dynamics, and impact (pp. 217-240). Hoboken, NJ: Wiley.

Page, E. H. (2004). Mental health services experiences of bisexual women and bisexual men: An empirical study. Binghamton, NY: Harrington Park/Haworth.

Pierce, C. (1970). Offensive mechanisms. In F. Barbour (Ed.), The Black seventies (pp. 265-282). Boston, MA: Porter Sargent.

Rainbow Health Ontario [RHO]. (2015). RHO fact sheet: Bisexual health fact sheet. Retrieved from http://www.rainbowhealthontario.ca/resources/bisexual-health-factsheet/ 
Rassi, S. L. (2011). US social work faculty and gender diversity concerns: Personal perspectives and curricular considerations (Doctoral dissertation, Michigan State University). Retrieved from https://deepblue.lib.umich.edu/bitstream/handle/2027.42/89752/mercury 1.pdf?seque nce $=1 \&$ is Allowed $=y$

Ristock, J. L. (2001). Decentering heterosexuality: Responses of feminist counselors to abuse in lesbian relationships. Women \& Therapy, 23(3), 59-72. doi: https://doi.org/10.1300/J015v23n03_05

Robinson, M. (2017). Two-spirit and bisexual people: Different umbrella, same rain. Journal of Bisexuality, 17(1), 7-29. doi: https://doi.org/10.1080/15299716.2016.1261266

Ross, L. E., Dobinson, C., \& Eady, A. (2010). Perceived determinants of mental health for bisexual people: A qualitative examination. American Journal of Public Health, 100(3), 496-502. doi: https://doi.org/10.2105/AJPH.2008.156307

Ross, L. E., O’Gorman, L., MacLeod, M. A., Bauer, G. R., MacKay, J., \& Robinson, M. (2016). Bisexuality, poverty, and mental health: A mixed methods analysis. Social Science \& Medicine, 156, 64-72. doi: https://doi.org/10.1016/j.socscimed.2016.03.009

Rust, P. R. (2000). Criticisms of the scholarly literature on sexuality for its neglect of bisexuality. In Bisexuality in the United States: A social science reader (pp. 5-10). New York: Columbia University Press.

Sands, R. G. (1996). The elusiveness of identity in social work practice with women: A postmodern feminist perspective. Clinical Social Work Journal, 24(2), 167-186. doi: https://doi.org/10.1007/BF02189730

Sarno, E., \& Wright, A. J. (2013). Homonegative microaggressions and identity in bisexual men and women. Journal of Bisexuality, 13(1), 63-81. doi: https://doi.org/10.1080/15299716.2013.756677

Sedgwick, E. K. (2007). Melanie Klein and the difference affect makes. South Atlantic Quarterly, 106(3), 625-642. doi: https://doi.org/10.1215/00382876-2007-020

Smith, L. C., Shin, R. Q., \& Officer, L. M. (2012). Moving counseling forward on LGB and transgender issues: Speaking queerly on discourses and microaggressions. The Counseling Psychologist, 40(3), 385-408. doi: https://doi.org/10.1177/0011000011403165

Steele, L. S., Ross, L. E., Dobinson, C., Veldhuizen, S., \& Tinmouth, J. (2009). Women's sexual orientation and health: Results from a Canadian population-based survey. Women \& Health, 49(5), 353-367. doi: https://doi.org/10.1080/03630240903238685

Steup, M. (2014). Epistemology. In E. N. Zalta (Ed.), The Stanford encyclopedia of philosophy. Retrieved from https://plato.stanford.edu/entries/epistemology/ 
Sue, D. W. (2010). Microaggressions in everyday life: Race, gender and sexual orientation. Hoboken, NJ: Wiley.

Sue, D. W., Bucceri, J., Lin, A. I., Nadal, K. L., \& Torino, G. C. (2007). Racial microaggressions and the Asian American experience. Cultural Diversity and Ethnic Minority Psychology, 13, 72-81. doi: https://doi.org/10.1037/1099-9809.13.1.72

Tangenberg, K. M., \& Kemp, S. (2002). Embodied practice: Claiming the body’s experience, agency and knowledge for social work. Social Work, 47(1), 9-18. doi: https://doi.org/10.1093/sw/47.1.9

Thoma, B. C., Huebner, D. M., \& Rullo, J. E. (2013). Unseen risks: HIV-related risk behaviors among ethnically diverse sexual minority adolescent females. AIDS Education and Prevention: Official Publication of the International Society for AIDS Education, 25(6), 535-541. doi: https://doi.org/10.1521/aeap.2013.25.6.535

Thoits, P. A. (2011). Resisting the stigma of mental illness. Social Psychology Quarterly, 74, 6-28. doi: https://doi.org/10.1177/0190272511398019

Tjepkema, M. (2008). Health care use among gay, lesbian and bisexual Canadians. Health Reports, 19(1), 53-64.

Voss, G., Browne, K., \& Gupta, C. (2014). Embracing the “and”: Between queer and bisexual theory at Brighton BiFest. Journal of Homosexuality, 61(11), 1605-1625. doi: https://doi.org/10.1080/00918369.2014.944055

Wallace, S. P., Cochran, S. D., Durazo, E. M., \& Ford, C. L. (2011). The health of aging lesbian, gay and bisexual adults in California. Policy Brief (UCLA Center for Health Policy Research). Retrieved from: https://www.ncbi.nlm.nih.gov/pmc/articles/PMC3698220/

Ward, B. W., Dahlhamer, J. M., Galinsky, A. M., \& Joestl, S. S. (2014). Sexual orientation and health among US adults: National Health Interview Survey, 2013. National Health Statistics Report, 77, 1-10.

Weiss, J. T. (2003). GL vs. BT: The archaeology of biphobia and transphobia within the US gay and lesbian community. Journal of Bisexuality, 3(3/4), 25-55. doi: https://doi.org/10.1300/J159v03n03_02

Wong, Y.-L. R. (2004). Knowing through discomfort: A mindfulness-based critical social work pedagogy. Critical Social Work, 5(1). Retrieved from http://www1.uwindsor.ca/criticalsocialwork/knowing-through-discomfort-amindfulness-based-critical-social-work-pedagogy

Author note: Address correspondence to: Gio Iacono, MSW, Factor-Inwentash Faculty of Social Work, University of Toronto, 246 Bloor Street West, Toronto, Ontario M5S 1V4.gio.iacono@mail.utoronto.ca

Acknowledgments: The author would like to thank Neelu Walia, Dr. Tara La Rose and Roz Spafford for their immense support and very helpful reviews of this article. The author would also like to thank Dr. Wendy Bostwick and Dr. Amy Hequembourg for 
providing inspiration and a solid theoretical framework to help generate critical discussions on bisexual well-being in the field of social work. 